\title{
The EU chemicals strategy for sustainability: in support of the BfR position
}

\author{
Frank A. Barile ${ }^{1}$ Sir Colin Berry ${ }^{2} \cdot$ Bas Blaauboer $^{3} \cdot$ Alan Boobis $^{4} \cdot$ Herrmann M. Bolt $^{5} \cdot$ Christopher Borgert $^{6}$. \\ Wolfgang Dekant ${ }^{7} \cdot$ Daniel Dietrich $^{8}$. Jose L. Domingo ${ }^{9} \cdot$ Corrado L. Galli $^{10} \cdot$ Gio Batta Gori $^{11} \cdot$ Helmut Greim $^{12}$ (D) \\ Jan G. Hengstler ${ }^{5}$. Pat Heslop-Harrison ${ }^{13}$. Sam Kacew ${ }^{14}$. Hans Marquardt ${ }^{15}$. Angela Mally ${ }^{7}$. Olavi Pelkonen ${ }^{16}$. \\ Kai Savolainen ${ }^{17} \cdot$ Emanuela Testai $^{18} \cdot$ Aristides Tsatsakis $^{19} \cdot$ Nico P. Vermeulen ${ }^{20}$
}

Received: 12 July 2021 / Accepted: 21 July 2021 / Published online: 7 August 2021

(c) The Author(s) 2021

\begin{abstract}
The EU chemicals strategy for sustainability (CSS) asserts that both human health and the environment are presently threatened and that further regulation is necessary. In a recent Guest Editorial, members of the German competent authority for risk assessment, the BfR, raised concerns about the scientific justification for this strategy. The complexity and interdependence of the networks of regulation of chemical substances have ensured that public health and wellbeing in the EU have continuously improved. A continuous process of improvement in consumer protection is clearly desirable but any initiative directed towards this objective must be based on scientific knowledge. It must not confound risk with other factors in determining policy. This conclusion is fully supported in the present Commentary including the request to improve both, data collection and the time-consuming and bureaucratic procedures that delay the publication of regulations.
\end{abstract}

Helmut Greim

helmut.greim@mytum.de

1 College of Pharmacy and Health Sciences, St John's University, Queens, NY, USA

2 Queen Mary University of London, London, UK

3 Division of Toxicology, Institute for Risk Assessment Sciences, Utrecht University, Utrecht, The Netherlands

4 National Heart and Lung Institute, Imperial College, London, UK

5 Leibniz Research Centre for Working Environment and Human Factors (IfADo), TU Dortmund, Dortmund, Germany

6 Applied Pharmacology and Toxicology, Inc., Gainesville, FL, USA

7 Department of Toxicology, University of Würzburg, Würzburg, Germany

8 Faculty of Biology, University of Konstanz, Konstanz, Germany

9 Laboratory of Toxicology and Environmental Health, School of Medicine, IISPV, Universitat 'Rovira I Virgili', Reus, Spain
10 Department of Pharmacological and Biomolecular Sciences, University of Milan, Milan, Italy

11 The Health Policy Center, Bethesda, MD, USA

12 Technical University of Munich, Munich, Germany

13 Department of Genetics and Genome Biology, University of Leicester, Leicester, UK

14 McLaughlin Centre for Risk Assessment, University of Ottawa, Ottawa, Canada

15 Toxicology, University of Hamburg, Hamburg, Germany

16 Department of Pharmacology and Toxicology, University of Oulu, Oulu, Finland

17 Nanosafety Research Centre, Finnish Institute of Occupational Health, Helsinki, Finland

18 Environment and Health Department, Instituto Superiore Di Sanità, Rome, Italy

19 Medical School, University of Crete, Crete, Greece

20 Department of Chemistry and Pharmaceutical Sciences, Vrije Universiteit, Amsterdam, The Netherlands 


\section{Commentary}

The declared objective of the EU Chemicals Strategy for Sustainability (CSS) is to "restore human health and environment to a good quality status" with respect to "substances of concern" (European Commission 2019). Examples, where it is thought by the CSS that there is concern and a need for better data, include exposures of vulnerable groups, endocrine-disrupting chemicals, and the risk assessment of mixtures.

In their Guest Editorial "EU chemicals strategy for sustainability questions regulatory toxicology as we know it: is it all rooted in sound scientific evidence?" published in this journal, several members of the German competent authority for risk assessment, the Federal Institute for Risk Assessment (BfR), raise concerns about the scientific justification for the CSS (Herzler et al 2021). We, as representatives of the international scientific community ${ }^{1}$ appreciate, that a competent authority, which stands for a science-based risk assessment of chemicals, may properly express concern about the need to "restore human health and environment to a good quality status". We are concerned that scientific data appear to be used as a justification for an intervention whereas the basis is "public concern".

We emphatically concur with the introductory remarks of the Guest Editorial:

Over the past decades, there has been an unprecedented regulatory drive in public health protection in the European Union, making large-scale toxicological incidents or mass poisonings such as, e.g. the thalidomide disaster of the 1950s-60 s or the Seveso incident in 1976 an issue of the past. Although this is rarely perceived by the media and the general public, the implementation of a complex and interdependent network of regulations for chemical substances, including industrial chemicals, plant protection products, biocides, or chemicals in food and feed has minimised toxicological risks and has continuously increased public health and wellbeing in the EU. Moreover, although this framework already provides one of the most advanced regulatory systems worldwide, it is constantly pressed for improvement by scientific progress as well as an ever-increasing public awareness.

The BfR points out that, despite several investigative efforts, there are no statistical data that support an apparent concern that in the EU chemical risk is an important or growing detrimental factor to human health.

In a carefully considered commentary, the BfR makes clear that in the necessary and continuous process of improving consumer protection any initiative taken must be based

$\overline{1}$ Present and past functions see Table 1 on state-of-the-art scientific knowledge and must include a broad discussion, taking into account the complex scientific, economic and societal issues involved. It is important not to confound scientific evidence for risk with other factors in determining policy.

In more detail the BfR authors address major deficiencies of the CSS proposal:

- The terms, "toxic-free" and "pollution" are not defined.

- A differentiation between hazard, exposure and risk needs to be addressed. Risk can only be quantified and managed when data on both potency and exposure provide information on whether a substance is likely to be harmful.

- No justification of the statement that "exposure to a mixture can give rise to adverse health and environmental effects, even at levels of exposure which are considered 'safe' for the individual chemicals on their own..." is provided. There appears to be a naïve assumption that all interactions will be additive.

- There is an implicit assumption that chemicals with an endocrine-disrupting potential are not sufficiently covered by the existing regulatory system in the EU. They do not need further regulation-all scientifically justified concerns are presently considered.

Instead of regulating non-existent or already well-considered risks, the BfR proposes that several existing faults or omissions, which slow down the regulation of dangerous chemicals should be rectified. These include,

- An ineffective and slow collection and consideration of available and relevant data.

- The time-consuming and bureaucratic procedures that delay the publication of regulations.

We also concur with further conclusions of the BfR authors:

- Thanks to the existing system of chemicals regulation in the EU, the current level of protection of its population as a whole, including sensitive sub-populations, against chemical risk is among the highest in the world. The rather bleak picture connoted in the CSS and its associated SWDs ${ }^{2}$ thus appears misplaced.

- A modern and enlightened society should base its decisions on the best scientific knowledge available.

- It is fully agreed that improvements to the existing regulatory procedures should be accelerated and streamlined, albeit not at the expense of scientific rigour, and that avail-

\footnotetext{
${ }^{2}$ Staff Working Documents.
} 
Table 1 Past and present affiliations of the authors

Frank A. Barile Ph.D.: Editor of Toxicology in vitro, past president of dermal toxicology specialty section of the Society of Toxicology Prof. Sir Colin Berry: Former chairman of the Advisory Committee on Pesticides, UK and of the Committee on Dental and Surgical Materials Prof. Bas Blaauboer: Former editor-in-chief of toxicology in vitro

Prof. Alan Boobis: Chair of the UK Committee on Toxicity, past chair of FAO/WHO JMPR and JECFA, Past President of EUROTOX, former Editor of Food and Chemical Toxicology

Prof. Hermann M. Bolt: Former chair of the Scientific Committee of Occupational Exposure Limits, Deputy Editor-in-Chief of Archives of Toxicology, Past President of EUROTOX

Christopher Borgert Ph.D.: President \& Principal Scientist Applied Pharmacology and Toxicology, Inc

Prof. Wolfgang Dekant: Former Editor-in-Chief of Toxicology Letters

Prof Daniel Dietrich: Editor of Chemico-Biological Interactions and of Computational Toxicology; Chair of Public-Private platform for the Prevalidation of testing methods on Endocrine Disruptors) Science Advisory Team; Elected external expert „Life Sciences for human well-being “ for the European Parliament

Prof Jose L. Domingo: Editor-in-Chief of Food and Chemical Toxicology

Prof. Corrado Galli: President of the Italian Society of Toxicology (SITOX)

Gio Batta Gori: Past Editor-in-Chief of Regulatory Toxicology and Pharmacology

Prof. Helmut Greim: Former chair of Scientific Committee on Health and Environmental Risks, Past President of the German Society of Pharmacology and Toxicology

Prof. Jan G. Hengstler: Editor-in-Chief of Archives of Toxicology

Prof. Pat Heslop-Harrison: Former Editor-in-Chief of Annals of Botany, Past President of Society for Experimental Biology, Vice-President European Cytogeneticists Association

Sam Kacew Ph.D.: North America Editor Toxicological and Environmental Chemistry, Associate Editor, Toxicology and Applied Pharmacology Prof. Hans Marquardt: Former Editor of Toxicology

Prof. Angela Mally: Editor in Chief of Toxicology Letters, Member of the Committee of Contaminants and other Undesirable Substances in the Food Chain of the BfR

Prof. Olavi Pelkonen: Former Specialty Chief Editor of Frontiers in Pharmacology and of Predictive Toxicology

Prof. Kai Savolainen: Editor-in-Chief of Human and Experimental Toxicology

Prof. Emanuela Testai: Co-Editor of Toxicology Letters, Vice-chair of the Scientific Committee for Health, Environmental and Emerging Risks

Prof. Aristides Tsatsakis: Editor of Food and Chemical Toxicology, Editor-in-Chief Toxicology Reports, past President \& Honorary member of EUROTOX

Prof. Nico Vermeulen: former Editor-in-Chief of Environmental Toxicology \& Pharmacology, Past President of the International Society for the Study of Xenobiotics

ability and accessibility of the data required for risk assessment still need to be improved significantly.

We support the BfR authors' request that a clear sciencebased evaluation should be made of whether additional measures are necessary to regulate what may be irrelevant risks. Action on "public concern" in the absence of scientific justification needs to be justified on other grounds. If the public concern is evident in well-regulated areas the real risk needs to be communicated to the public more effectively. Finally, as the implementation of sustainable development is mentioned repeatedly, a clear definition and stringent requirements for implementation need to be provided by the CSS.

We hope that the critical evaluation of the CSS by the BfR will trigger a science-based debate on the different aspects addressed in the CSS. Otherwise, CSS remains a document without scientific justification.
Funding Open Access funding enabled and organized by Projekt DEAL. The authors received no compensation for this Commentary.

\section{Declarations}

Conflict of interest The authors declare no conflict of interest.

Open Access This article is licensed under a Creative Commons Attribution 4.0 International License, which permits use, sharing, adaptation, distribution and reproduction in any medium or format, as long as you give appropriate credit to the original author(s) and the source, provide a link to the Creative Commons licence, and indicate if changes were made. The images or other third party material in this article are included in the article's Creative Commons licence, unless indicated otherwise in a credit line to the material. If material is not included in the article's Creative Commons licence and your intended use is not permitted by statutory regulation or exceeds the permitted use, you will need to obtain permission directly from the copyright holder. To view a copy of this licence, visit http://creativecommons.org/licenses/by/4.0/. 


\section{References}

European Commission (2019) Communication from the commission to the European Parliament, the council, the European economic and social committee and the committee of the regions: the European green deal. COM (2019) 640 final, date: 2019-12-11. 52019DC0640-EN-EUR-Lex, European Union

Herzler M, Marx-Stoelting P, Pirow R, Riebeling C, Luch A, Tralau T, Schwerdtle T, Hensel A (2021) The "EU chemical strategy for sustainability" questions regulatory toxicology as we know it: is it all rooted in sound scientific evidence? Arch Toxicol 95:2589-2601

Publisher's Note Springer Nature remains neutral with regard to jurisdictional claims in published maps and institutional affiliations. 